\title{
Analysis and Discussion on Burning Low Calorific Value Fuel of Circulating Fluidized Bed Boiler
}

\author{
Yi Yan \\ School of Energy and Power Engineering, Huazhong University of science and technology, Wuhan, China.
}

\begin{abstract}
China's coal-dominated energy structure will not change in a short time. In order to implement the relevant national policies on energy conservation and emission reduction, it is a good response to adopt circulating fluidized bed boilers in coal-fired power stations. Circulating fluidized bed boiler adopts fluidized combustion, which has high reliability and high utilization rate because of its special combustion mode and particle recycling device. For the low calorific value inferior fuel which is difficult to burn in common boiler, CFB boiler also has certain adaptability and compatibility. In this background, this article with coal gangue as the representative of the inferior coal are discussed its application in the circulating fluidized bed boiler, the combustion process, boiler equipment and special fly ash produced by combustion is proposed that often appear in the three aspects of problems, and accordingly put forward the solution and optimization measures, provides reference for the actual process.
\end{abstract}

Key words: Circulating fluidized bed boiler; Low calorific value fuel; Operation problem; Retrofit scheme.

\section{Introduction}

Circulating fluidized bed combustion technology, a new combustion technology which has been widely built and running in modern thermal power stations, is relatively mature and can achieve clean combustion. When the air flow passes through a bed where solid particles are accumulated, if its flow rate reaches such a level that the frictional resistance between the fluid and the particles is just equal to its net gravity, solids will be suspended to have certain fluid appearance characteristics, which is called fluidization. Fluidized bed combustion shows this phenomenon. Continue to increase the air flow rate, when it exceeds a certain speed, the particles will just be blown out of the combustion chamber, but if a separator is installed at the outlet end to capture solid particles according to their size, the unburned particles can be captured from the flue gas and sent back to the combustion chamber for circular combustion through the return feeder, so that the fuel can be recycled, which is called circulating fluidized bed combustion technology. Therefore, compared with other types of boilers, it is easier to deconstruct inferior fuels and further decompose the nonflammable parts. The fly ash obtained from combustion can also be returned to the furnace to improve its burnout rate. The bed materials for fluidized bed combustion are not limited to traditional fossil fuels, but also include solid wastes and various biomass fuels. Because of its advantages of high combustion efficiency, wide adaptability to coal types, uniform temperature distribution in combustion chamber and large load regulation interval, through research, the basic principles of heating, mechanics, materials and other engineering problems such as overtemperature of heating surface, expansion of furnace body and wear of materials have been well solved. Circulating fluidized bed technology has been in a priority position in the field of clean coal power generation in China [1-3].

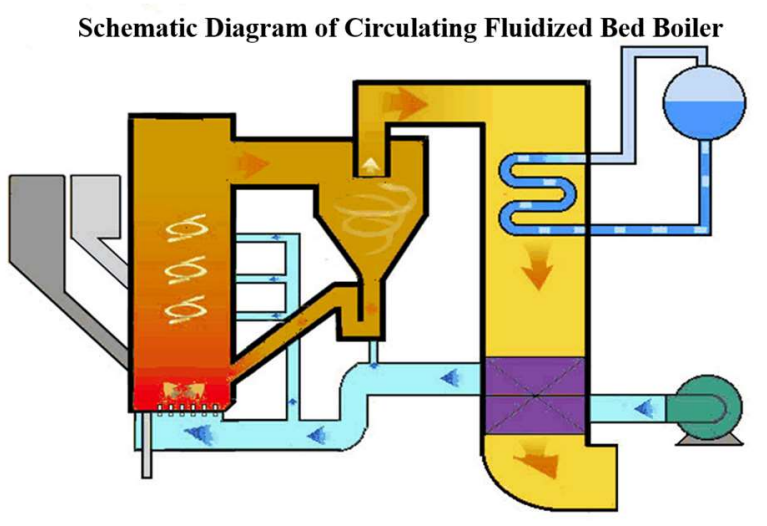

Fig 1. Schematic Diagram of Circulating Fluidized Bed Boiler

Coal gangue is a black rock that is mixed with organic and inorganic compounds co-deposited with coal during the coal formation process. It is a solid waste discharged during the process of excavation, mining and coal washing. It has low carbon content and hard texture. Coal occupies an absolutely dominant position in Chinese energy utilization, and a large amount of coal gangue has

\footnotetext{
*Corresponding author: u201812078@hust.edu.com
} 
been accumulated during the long-term mining and utilization of coal. The coal gangue pile not only covers a large area, but also after a long period of sun and rain, it may cause spontaneous combustion and cause an explosion, releasing a large amount of dust and harmful gases, which seriously affects the air quality of the surrounding environment [4-5]. At the same time, as a resource, coal gangue is a kind of inferior fuel with utilization value, and it is of practical significance to mix and burn with coal.

Circulating fluidized bed boilers designed according to a specific fuel or coal are not suitable for other fuels with different properties. However, based on the economical operation and the extensive utilization of CFB technology, some coal-fired power stations choose to mix and burn coal with different properties from the design coal, so the combustion conditions in the furnace will deviate from the design value during actual operation. As a result, the fuel consumption of the whole plant increased and the economy decreased. Based on this, taking coal gangue as an example, this paper will discuss the possible problems when burning low calorific value fuel in circulating fluidized bed boiler from three aspects and put forward corresponding solutions.

\section{Combustion Conditions}

Coal gangue has complex chemical composition, low fixed carbon content and low calorific value, and its calorific value is generally $3000 \sim 11000 \mathrm{~kJ} / \mathrm{kg}$. The ash content is generally over $60 \%$, up to $90 \%$, and the main components in the ash are aluminum oxide and silicon dioxide. Some coal gangue also has the characteristics of high sulfur content and high hardness. All these will have an adverse effect on combustion [6].

\subsection{Difficulties in Ignition and Extinguishment}

First of all, due to the uneven distribution of fuel particle size, the part composed of finer particles is easy to catch fire, while the large particles are difficult to decompose and ignite, which leads to the difficulty of boiler operation. In the initial stage of power plant application, deflagration occurred due to large input. In the later application, although deflagration no longer occurs, the volatile matter of coal is too low. It is very difficult for boiler to catch fire, volatile matter cannot be precipitated stably, which leads to unstable combustion state and slow rise of bed temperature. After the hearth is in a burning state, the bed layer is an area where coal gangue and air are preliminarily mixed, and the burning is intense, so it is impossible to control the bed temperature to drop in a short time, which makes it difficult for the boiler to extinguish the fire. In addition, the high temperature of the primary air chamber adjacent to the bed easily causes the burner under the bed to burn out due to overtemperature. After analyzing the characteristics of this kind of refractory coal and certain tests, the following methods can be adopted to solve the problem of ignition and fire extinguishing difficulties:
(1) Choose higher combustion share in dense phase zone. At the initial stage of ignition, more fine particles are put in, which makes the combustion share of dense phase zone in the lower bed of furnace larger. Fine particles are easy to burn and release more heat, which makes the bed temperature rise rapidly and reach a stable combustion state. After the bed temperature is normal, large particles are put into combustion step by step.

(2) Adopt higher primary air rate. Under the condition of (1), high primary air rate must be used at the same time to bring the released heat out of dense phase zone, avoid local high temperature caused by excessive heat accumulation, and send the heat to the dilute phase zone where the upper combustion temperature is still low, so as to improve the upper combustion conditions and make the whole furnace heat load uniform. However, when a higher fluidization speed is adopted, under the condition of the same cycle ratio, the residence time of fuel particles in the combustion area may be short, which may reduce the combustion efficiency; When the fluidization velocity is lower, besides the above-mentioned overtemperature phenomenon, it may also cause the deposition of large particles and coke on the nearby water wall. Therefore, it is necessary to ensure that the fluidization speed is in a proper range.

(3) Because the volatile matter content and calorific value of coal gangue are low, and the heat release in dense phase area is less, in order to prevent the bed temperature from being too low at the initial ignition stage, the amount of circulating materials should be reduced to reduce the heat carried by the burnt particles transported back by the return feeder, and the lower circulation ratio can be adopted, which can be realized by appropriately reducing the fluidization speed.[7] 


\subsection{Local High Temperature in Dense Phase Area of Mixed Coal Burning Stone.}
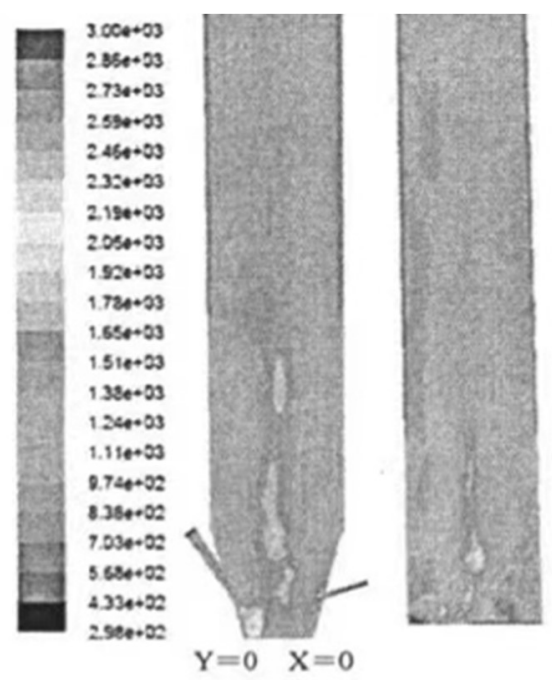

Longitudinal section temperature distribution

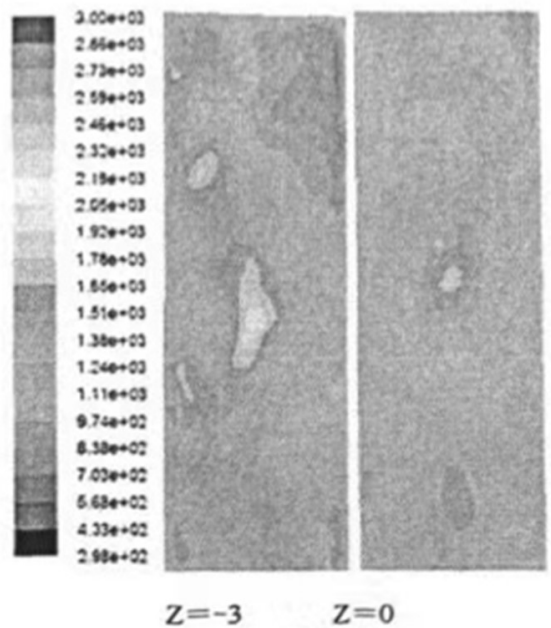

Cross section temperature distribution

Fig. 2. Temperature distribution in furnace

When burning coal gangue, a high temperature zone appears in the dense phase area above the coal feeding port close to the front wall, and the temperature could reach more than $1000 \mathrm{~K} \mathrm{~K}$. This is because when the mixed particles of coal gangue and pulverized coal are blown up and burned, the airflow near the side wall appears backflow phenomenon, which is mixed with the primary air coming out from the bottom, and the coal gangue particles with larger density and volume are in the bed. Continuous combustion on the surface and unable to bring out the heat generated by the combustion in time. The occurrence of this phenomenon on the one hand causes the high temperature area to stick to the front wall, causing the heating surface to coke, and it is easy to cause over-temperature damage to the air distribution plate under the bed; on the other hand, it blocks the upward flow of primary air and affects the fluidization state in the combustion chamber. This causes uneven heat absorption of the water wall on the radiant heating surface, and reduces the combustion efficiency in the dilute phase zone.
Existing boiler operation cases show that the above phenomenon is particularly obvious when coal is mixed with $20 \%$ coal gangue, which can be solved by adjusting the secondary air volume, especially by increasing the air intake of the secondary tuyere of the side wall of dense phase area to realize large-scale interference to the return air flow, so that it can be realized in the mixed flow in three-dimensional space. Prevent hot air from staying near the bed for too long, which can optimize the fluidization state. In addition, pre-throwing coal gangue with finer particles mentioned in the above-mentioned ignition and fire extinguishing difficulties can also effectively alleviate this problem, so it is necessary to increase the grinding intensity of coal in the coal pulverizing system and the separation accuracy of the separator. When $10 \%$ coal gangue is blended, due to the small proportion of coal gangue, it can't have much influence on the whole combustion situation, there is no obvious flame sticking to the wall in dense phase area, and the temperature distribution in the furnace is relatively uniform as a whole, so the damage phenomenon of heating surface in boiler operation is obviously reduced.[8]

\section{Boiler and Its Auxiliary Equipment}

\subsection{Coal Transportation and Slagging}

Since the calorific value of coal gangue is generally low, when the boiler load is constant, the coal consumption of the boiler increases, the ash produced in the furnace increases, and the slag discharge increases, thus increasing the use frequency of slag cooler and slag conveyor, and shortening the service life when overloaded. When the boiler ash is large, it is easy to block the slag discharge pipe, but it cannot discharge slag normally for a long time. Ash will accumulate on the bed to block the feeding and block the passage of primary air from the bottom. In severe cases, it will lead to coking of the bed and aggravate the blocking phenomenon. However, most coal gangue is hard and hard to grind, so it puts forward higher requirements for the mechanical strength of coal mills, which increases the use failures of coal mills, separators and other equipment suitable for ordinary coal quality. Operation and maintenance costs of the pulverizing system increase.

Low calorific value and large ash content increase the operation burden and failure frequency of the coal conveying and slag removal system. If it is planned to burn coal gangue with poor quality for a long time, the traditional wind-water combined slag cooler unit often has the problem of insufficient slag discharge capacity when the slag discharge amount is large, and if unburned combustible materials are discharged into the wind-water slag cooler, its continuous combustion will lead to coking and burning of slag cooler. After a large number of large fluidized bed units have been put into operation in China, the practical results show that the slag discharge capacity can be improved and the problem of slag blockage can be solved by changing to the drum slag cooler. Because the slag is always driven to rotate by the roller in the roller slag cooler, there is no dead angle which is easy to deposit 
in the structure. And is easy to be fully cooled, so coking phenomenon is not easy to occur; In addition, the roller slag cooler makes use of the pressure difference between the hearth and its interior to make the slag automatically enter the slag cooler through the slag dropping pipe, so its structure is simpler and its volume is smaller than that of the wind-water combined slag cooler.

\subsection{Sulfur Content}

Coal gangue generally contains a large amount of sulfur, and its sulfur substances burn to form composite sulfate, which condenses on the outer wall of water wall at high temperature, destroys the oxide film on it, gradually reduces the thickness of pipe wall, and finally leads to pipe explosion; While in the economizer and air preheater where the wall temperature is lower than the dew point of flue gas, Sulphuric acid steam produced by a series of reactions such as combustion will corrode at low temperature, destroy materials and affect the normal operation of two kinds of equipment. And when the sulfur content of fuel is large, the deformation temperature DT of ash decreases, which makes the return feeder and bed more prone to coking under the condition of keeping the same combustion temperature in the circulation loop.

When the sulfur content is high, it is necessary to combine desulfurizer with flue gas desulfurization to meet the environmental protection requirements. In order to achieve desulfurization efficiency, the desulfurizer is mixed in the fuel, and a higher $\mathrm{Ca} / \mathrm{S}$ ratio is adopted. The desulfurizer captures the generated sulfur oxides in time, reducing the content of the latter in the flue gas, and the products will be discharged together with ash and slag without pollution. ${ }^{[9]}$ at the same time, the flue gas desulfurization device is added, which requires higher desulfurization efficiency than the traditional wet desulfurization technology.

\section{About Fly Ash}

Strictly speaking, a series of problems caused by fly ash from combustion belong to the combustion conditions and the loss of machinery and equipment easily caused by burning low calorific value fuel (coal gangue) in circulating fluidized bed boiler discussed before, but according to statistical data, the problems generated in the operation process account for a large proportion of the whole. This kind of problem becomes particularly obvious when burning coal gangue, so it is discussed separately.

\subsection{Fly Ash Erosion}

\subsubsection{Abrasion of Heating Surface}

In a circulating fluidized bed boiler burning coal gangue and other fuels with low calorific value and high ash content, due to the large amount of fly ash in flue gas and high flue gas flow rate, in which the content of solid particles is much larger than that of ordinary pulverized coal boilers, the wear caused by scouring the furnace wall and heating surfaces at all levels is much more serious than that of traditional boilers. The wear of solid surface caused by a large number of particles carried by flue gas can be divided into two types: scouring wear and impact wear.

Erosion wear refers to the impact of solid particles on the material surface at a small angle relative to the solid surface. The partial velocity parallel to the normal of the solid surface makes the particle wedge into the object surface, while the partial velocity parallel to the tangent of the solid surface makes it still slide along its surface after wedging. The combined effect of these two partial velocities plays a "cutting" role. When the strength of the surface material is not enough to bear the impact, a tiny tissue structure will be cut off. This kind of phenomenon occurs constantly, and local materials on the surface are continuously lost, which will lead to obvious wear.

Impact wear refers to the larger impact angle of particles relative to the solid surface. This kind of impact makes the surface structure produce tiny plastic deformation or microcrack along the depth direction, which reduces the strength or fatigue of the material; Under the repeated impact of a large number of particles, the whole plastic deformation layer gradually falls off to form wear [10].

\subsubsection{Anti-Abrasion Measures}

The data show that the wear of the heating surface and furnace wall in the furnace is mainly scouring wear. The reason of wear is that the kinetic energy of ash particles will destroy it when it hits the wall. The analysis shows that the wear problem of heating surface exists in two aspects: particle and worn structure. Therefore, the concrete measures can be divided into two aspects: improvement of boiler operating conditions and equipment management and transformation. It is complicated and costly to replace all the materials that are easy to wear, so it can be realized by installing anti-wear structures at the parts that are easy to wear [11].

In terms of operation optimization, the following measures can be taken:

(1) Reasonable air distribution. Specifically, it can be realized by reducing the air volume of primary air at the bottom and increasing the air volume of transverse secondary air, so as to reduce the flue gas flow rate while ensuring the combustion efficiency.

(2) Reduce the ash concentration. Specifically, it can be realized by appropriately reducing the primary air volume and excess air coefficient, strengthening the grinding strength and reasonably controlling the particle size of the incoming particles below a certain level.

In terms of equipment management and transformation, the following measures can also be taken to reduce wear and tear:

(1) metal surface grinding and spraying.

(2) Thick-walled pipes are used locally. In places that may be seriously worn, a section of thick-walled pipe should be properly used to prolong the service life.

(3) Reasonable construction of bosses. Control the height of anti-wear bosses, and repair the anti-wear bosses of 
water walls at four corners of the furnace to areas with low particle concentration.

(4) Install anti-wear beams. The characteristics of hydrodynamic field in circulating fluidized bed boiler determine that the root of fly ash wear lies in the wall flow in the boiler. Anti-wear beam can reduce the ash concentration and velocity of wall-attached flow by setting multiple obstacles on the outer surface of water wall to ensure reasonable structure and heat transfer performance, thus reducing the fly ash wear of heating surface.

\subsection{Large Loss of Carbon Residue in Fly Ash}

When coal gangue is burned, the carbon residue in fly ash can be as high as $20-40 \%$ or more, which greatly increases the loss of incomplete combustion of solid. But this is also a problem that can be solved, is being solved or has been partially solved. In the past, measures such as increasing excess air coefficient, increasing furnace temperature or air temperature, and feeding with positive pressure were taken, but the improvement effect was not significant or even decreased. It is effective to recycle the fly ash into the combustion chamber, but the particle size of the fly ash is small and the activity of carbon residue has decreased, so the complete combustion of carbon residue still cannot be realized. At present, the most effective measure is to send the fly ash to an external special furnace to gasify and burn it, which can further burn the residual carbon and remove more than 95\%. The discharged ash can be directly used as building materials.[12]

\section{Conclusion}

This paper first introduces the working principle of circulating fluidized bed boiler, and points out its main characteristics as a clean combustion technology, especially highlights its wide adaptability to various fuels. Evidently, as most of low-calorific fuels are characterized by their poor quality, various problems will inevitably arise in the combustion process. In this paper, coal gangue is taken as an example. This paper expounds from the following three aspects, and puts forward feasible solutions:

(1) Due to the difference between coal gangue and pulverized coal, some problems that will not occur in the combustion of the latter frequently occur in the combustion conditions of the former, such as difficult ignition, unstable combustion and local high temperature in dense phase zone, etc. Production practice has proved that adopting lower circulation ratio and properly mixing pure pulverized coal to drive coal gangue to burn can appropriately reduce the above problems.

(2) The combustion of inferior fuel is easy to increase coal consumption and produce a large amount of slagging, which will have adverse effects on coal mills, slag coolers and other equipment. High-strength pulverizing system can be adopted and corresponding equipment can be modified to adapt to working conditions; The problem of high sulfur content in inferior fuel can be solved by desulfurization agent in furnace and desulfurization treatment of flue gas.

(3) The problems caused by fly ash are various, among which the problem of high residual carbon can be improved by using the special structure of CFB boiler. However, the serious wear problem of heating surface is closely related to the physical and chemical properties of inferior fuel, so the loss can only be avoided by pretreating fuel and strengthening the structure of boiler related equipment.

\section{References}

1. Yue G., Lu J., et al. The Up-To-Date Development and Future of Circulating Fluidized Bed Combustion Technology [J]. Electric Power, 2016,49(1):1-13.

2. Feng C., Yue G., et al. Circulating fluidized bed combustion boiler [M]. Beijing: China Electric Power Press, 2003.

3. Wang Z., Pan L., et al. Review of present situation and prospect for clean development of coal-fired power in China [J]. Electric Power Technology and Environmental Protection, 2018,34(1):1-8.

4. Liu R., Wang Q., \& Liu J. Hazards and Countermeasures of the Gangue in Northeast of China [J]. Journal of Geographical Sciences, 2002, 22(1):110-113.

5. Jiang H. Harm of coal gangue to environment and its comprehensive treatment and utilization $[\mathrm{J}]$. Coal Processing \& Comprehensive Utilization, 2003, (3):43-46.

6. Lou B., Shi J. The Problem Analysis of Cocombustion of Coal and Coal Gangue in CFB Boiler [J]. Power System Engineering, 2009,25(05):21-22.

7. Sin L., Pan J., \& Wu H. The Commissioning and Operation of Coal-gangue-fired CFB Boilers. 2006, 027(003):36-40.

8. Wang F. Numerical Simulation and Combustion Optimization of Circulating Fluidized Bed Boiler Mixed with Coal Gangue [D]. South China University of Technology, 2011.

9. Zheng G. Influence of coal quality change on combustion of circulating fluidized bed boiler and countermeasures $[\mathrm{J}]$. Shandong Coal Science and Technology, 2007(04):21+23.

10. Zhang H. Study on Wear Mechanism and Anti-wear Measures of CFB Boiler Water Wall [D]. North China Electric Power University (Beijing), 2011.

11. Wang $X$. Equipment management and operation optimization of $300 \mathrm{MW}$ circulating fluidized bed boiler [D]. north China electric power, 2012.

12. Zhao Z. Progress in industrial application of fluidization technology-on the development of fluidized bed boilers with inferior fuel [J]. Chemical Engineering, 1974(01) 